\title{
Effect of Exercise on Serum Sex Hormones in Men: A 12-Month Randomized Clinical Trial
}

\author{
VIVIAN N. HAWKINS ${ }^{1,2}$, KAREN FOSTER-SCHUBERT ${ }^{1,3}$, JESSICA CHUBAK ${ }^{1,2}$, BESS \\ SORENSEN ${ }^{1}$, CORNELIA M. ULRICH ${ }^{1,2,3}$, FRANK Z. STANCYZK ${ }^{4}$, STEPHEN PLYMATE $^{3,5}$ \\ JANET STANFORD ${ }^{2,6}$, EMILY WHITE ${ }^{1,2}$, JOHN D. POTTER ${ }^{1,2}$, and ANNE MCTIERNAN ${ }^{1,2,3}$ \\ ${ }^{1}$ Cancer Prevention Program, The Fred Hutchinson Cancer Research Center, Seattle, WA \\ 2 Department of Epidemiology, School of Public Health and Community Medicine, University of \\ Washington, Seattle, WA \\ ${ }^{3}$ Department of Medicine, School of Medicine, University of Washington, Seattle, WA \\ ${ }^{4}$ School of Medicine, University of Southern California, Los Angeles, CA \\ ${ }^{5}$ Geriatric Research and Education Clinical Center, Veterans Affairs Puget Sound Health Care \\ Systems, Seattle, WA \\ ${ }^{6}$ Division of Public Health Sciences, The Fred Hutchinson Cancer Research Center, Seattle, WA
}

\begin{abstract}
Purpose-The effect of exercise on androgens in middle-aged to older men is poorly understood, and it could have implications for several aspects of health. This analysis was conducted to examine the effects of long-term aerobic exercise on serum sex hormones in middleaged to older men.

Methods-One hundred two sedentary men, ages 40-75 yr, were randomly assigned to a 12month exercise intervention or a control group (no change in activity). The combined facility- and home-based exercise program consisted of moderate/vigorous-intensity aerobic activity for 60 $\min \cdot \mathrm{d}^{-1}, 6 \mathrm{~d} \cdot \mathrm{wk}^{-1}$. Serum concentrations of testosterone, free testosterone, dihydrotestosterone (DHT), $3 \alpha$-androstanediol glucuronide ( $3 \alpha$-Diol-G), estradiol, free estradiol, and sex hormonebinding globulin (SHBG) were measured at baseline, 3, and 12 months.
\end{abstract}

Results-Exercisers trained a mean of $370 \mathrm{~min} \cdot \mathrm{wk}^{-1}$ (102\% of goal), with only two dropouts. Cardiopulmonary fitness $\left(\mathrm{VO}_{2 \max }\right)$ increased $10.8 \%$ in exercisers and decreased by $1.8 \%$ in controls $(P<0.001)$. DHT increased $14.5 \%$ in exercisers versus $1.7 \%$ in controls at 3 months $(P=$ $0.04)$; at 12 months, it remained $8.6 \%$ above baseline in exercisers versus a $3.1 \%$ decrease in controls $(P=0.03)$. SHBG increased $14.3 \%$ in exercisers versus $5.7 \%$ in controls at 3 months $(P=$ $0.04)$; at 12 months, it remained $8.9 \%$ above baseline in exercisers versus $4.0 \%$ in controls $(P=$ 0.13 ). There were significant trends toward increasing DHT and SHBG, with greater increases in $\mathrm{VO}_{2 \max }$ at 3 and 12 months in exercisers. No statistically significant differences were observed for testosterone, free testosterone, $3 \alpha-$ Diol-G, estradiol, or free estradiol in exercisers versus controls.

Conclusions-A yearlong, moderate-intensity aerobic exercise program increased DHT and SHBG, but it had no effect on other androgens in middle-aged to older men.

Address for correspondence: Anne McTiernan, M.D., Ph.D., Fred Hutchinson Cancer Research Center, PO Box 19024, M4-B402, Seattle, WA 98109-1024; amctiern@ @hcrc.org.

V.N.H. and K.F.S. contributed equally to the manuscript. 


\section{Keywords}

AEROBIC EXERCISE; ANDROGENS; HUMAN MALES; ADIPOSITY

An age-associated decline of serum testosterone after the fourth to fifth decades of life in men has been observed not only cross-sectionally (61), but also longitudinally in large cohort studies $(13,65)$. A combination of changes in testicular function, altered neuroendocrine regulation of Leydig cells, and increased binding capacity of sex hormonebinding globulin (SHBG) results in approximately $40 \%$ lower testosterone levels among men in their 70 s compared with men in their 20 s $(12,25,28)$. Given the many health changes that also occur in men as they age, the possibility of a relationship between the decline in androgens and these health changes has, not surprisingly, been an area of active investigation. Low levels of testosterone in men have been associated with decreased sexual function, loss of muscle mass and strength, osteoporosis, declining cognitive function, and poorer quality of life (28). Further, the age-related decline in testosterone is associated with increased body fat, insulin resistance, and other metabolic risk factors (36). Despite the common belief to the contrary, cardiovascular disease has been associated with low levels of androgens in older men (23).

Although treating men with clinical androgen deficiency with testosterone replacement is clearly beneficial for several health and quality-of-life outcomes, administering testosterone to older men with aging-associated relative androgen deficiency is controversial and likely not beneficial $(6,16)$. Yet, there is some evidence that increasing sex hormone levels in aging men may provide health benefits such as improved cognition, enhanced sexual function, and reduced frailty (28). Rather than administering pharmacologic doses of exogenous testosterone, interventions that favorably alter endogenous sex hormone levels could be of greater benefit in this setting. One such possible intervention is exercise.

The majority of studies exploring the effects of exercise on androgens have focused on acute effects in short-term exercise protocols, and most of these demonstrate that exercise bouts are associated with an acute transient increase in testosterone, with variable effects on other androgens when these are measured $(8,14,18,20,31,63)$. The effect of long-term, moderateintensity, aerobic exercise on hormone levels in men has not been well studied, yet it may be important to differentiate between the acute and chronic effects of exercise, as acute changes may relate more to muscle growth and tissue remodeling, whereas chronic changes may mediate exercise effects on long-term health $(24,32)$. Some cross-sectional studies conducted in middle-aged and older men indicate that circulating testosterone concentrations may be higher in men who regularly exercise $(3,40)$. Prospective, nonrandomized studies of resistance exercise over a few weeks either increased testosterone (50) or not $(26,42)$, whereas one study of daily aerobic exercise together with a low-fat diet increased SHBG, which could counteract the biological activity of testosterone (60). To our knowledge, no randomized clinical trials have been published that have tested the chronic effects of aerobic exercise on a comprehensive panel of sex hormones in middle-aged to older men. Thus, there is no consensus regarding the physiologic role of long-term exercise to alter hormone levels in men and, in turn, impact age-related diseases.

We conducted a randomized clinical trial to examine the effects of a 12-month, moderateintensity, aerobic exercise intervention on serum testosterone, free testosterone, dihydrotestosterone (DHT), $3 \alpha$-androstanediol glucuronide ( $3 \alpha-$ Diol-G), estradiol, free estradiol, and SHBG in sedentary men. DHT is synthesized from testosterone by two isoenzymes of $5 \alpha$-reductase (Fig. 1) and is more biologically active at the androgen receptor than testosterone, whereas $3 \alpha$-Diol-G is its inactive metabolite. Because obesity is 
associated with sex hormones (28), we assessed the effects of the exercise intervention on serum hormones by baseline BMI and body fat, and by change in adiposity over 12 months. We additionally evaluated the effects of exercise on sex hormones by baseline age and baseline testosterone level. Among exercisers, the effect of the intervention on serum hormones by adherence and changes in fitness were also evaluated. All of these exploratory subgroup analyses were preplanned.

\section{METHODS}

The study was a randomized clinical trial comparing the effects of a 12-month, moderateintensity, aerobic exercise intervention versus maintenance of a sedentary lifestyle control on circulating sex hormone levels measured at baseline, 3 months, and 12 months. All study procedures, including written informed consent, were reviewed and approved by the Fred Hutchison Cancer Research Center institutional review board.

\section{Participants and randomization}

Participants were ages 40-75 yr, physically inactive (i.e., engaging in less than $90 \mathrm{~min} \cdot \mathrm{wk}^{-1}$ of moderate- or vigorous-intensity exercise, or having a $\mathrm{VO}_{2 \mathrm{max}}$ indicating low fitness level (44), nondieting, consuming fewer than two alcohol drinks per day, nondiabetic, without personal history of invasive cancer or other serious medical conditions such as cardiovascular disease or stroke, with a normal response to a maximal exercise tolerance test (maximal effort defined by participant self-reported fatigue with achievement of a respiratory exchange ratio $\left(\mathrm{VCO}_{2} / \mathrm{VO}_{2}\right)>1.0$ without evidence of ischemia or severe arrhythmia, or cardiology clearance after a positive test), and with normal complete blood count and blood chemistries. Additional details have been published previously $(37,39)$.

Several methods were used to recruit participants from 2001 through 2004. Because this study was part of a trial designed to test exercise effects on biological markers of colorectal cancer risk, the primary method was through gastroenterology practices. Potentially eligible men who had undergone colonoscopy were identified and sent an invitation letter by their physician with an enclosed interest survey to complete and return. From the 4907 letters that were mailed, 966 (19.7\%) responded expressing interest in joining the study, and of these, $151(15.6 \%)$ were deemed eligible after a phone interview and a postinterview information session (Fig. 2). Additional recruitment methods included media placements, flyers, a study Web site, and referrals. A total of 202 men attended an information session, 145 were screened in clinic, and 102 men were enrolled. The major reasons for ineligibility were unwillingness to be randomly assigned to exercise or control groups, being too physically active, and not having time available to attend facility classes.

Participants were randomized by the study coordinator via a computerized program to exercise or control group (referred to, respectively, as exercisers and controls), blocked on use of NSAIDs (two or more times per week vs less), and smoking status (yes vs no). End points were measured by staff blinded to randomization status. Informed consent was obtained following the requirements of the Fred Hutchinson Cancer Research Center institutional review board. Participants were paid $\$ 50$ and $\$ 75$ after completion of baseline and 12-month data collection, respectively.

\section{Intervention}

The intervention was a 12-month facility-and home-based exercise program. The prescription was $6 \mathrm{~d} \cdot \mathrm{wk}^{-1}$ of $60 \mathrm{~min}$ per session of moderate-to-vigorous aerobic exercise gradually achieved over the first $12 \mathrm{wk}$, with an additional 5-10 min of warm-up, cooldown, and stretching. Three days per week, participants exercised on treadmills, elliptical 
machines, rowers, and stationary bikes, with an exercise specialist present at one of four facilities (one located at the FHCRC Prevention Center, A. McTiernan, director; and three private health clubs). Participants were given Polar heart rate monitors (Polar Electro Inc., Lake Success, NY), with a prescription corresponding to $60-85 \%$ of their maximal heart rate on their baseline $\mathrm{VO}_{2 \max }$ test. Participants also were asked to exercise at home or at the gym three additional days per week with the same instructions regarding duration and heart rate goal ranges.

After each facility session, participants made an entry onto a facility log including their exercise duration, intensity, and maximal heart rate. The exercise specialist monitored each participant's progress in relation to their individual heart rate ranges. The participants were taught that as they became more fit, it would take more effort to attain their target heart rate range. The exercise specialist directed safe increases in the cardio machine settings to ensure that participants achieved their desired heart rate during facility workouts. By then recording duration, intensity, and maximal heart rate for each session, participants became more adept at self-monitoring. Exercisers were not assigned a weight loss program and were asked not to change their dietary habits during the 12-month duration of the trial.

Multiple strategies were used to achieve and maintain adherence, including regular monitoring and feedback, monthly progress review meetings with behaviorally trained exercise specialists, newsletters, incentives (e.g., water bottles), and group social events. Several methods were employed to monitor and measure adherence to the exercise intervention, including facility class attendance (with data on type, length, and maximal heart rate entered on facility logs, verified by the exercise specialist, and data entered), home exercise logs (with data on type, length, and maximal heart rate entered, submitted weekly, reviewed by the exercise specialist, and data entered), quarterly Minnesota Leisure Time Physical Activity Questionnaire (MNLTPA) interviews, quarterly use of pedometers for 1 wk with logging of steps, and $\mathrm{VO}_{2 \max }$ treadmill tests at baseline and 12 months. Adherence was calculated weekly from logs as facility and home sessions completed, total minutes per week, MET-minutes per week, and percentage of goal $360 \mathrm{~min} \cdot \mathrm{wk}^{-1}$ of exercise. Good adherence was defined as meeting at least $80 \%$ of the overall minutes-per-week goal of moderate-to-vigorous exercise, such that for participants meeting less than this goal for two or more weeks, special assistance was used to help them increase their level of participation.

\section{Controls}

Controls were asked not to change their exercise or dietary habits during the 12-month duration of the trial. After completing each quarter of the study, they used a pedometer to record their number of steps per day for $7 \mathrm{~d}$, and they participated in the MNLTPA physical activity interviews. After completion of all end-of-study measures, they were given the opportunity to participate in exercise classes for 2 months.

\section{Baseline, 3-month, and 12-month follow-up measures}

Demographic and medical history information were collected at baseline, 3, and 12 months, including health habits, medications, history of chronic diseases, and body weight history. Total caloric intake was measured at baseline and 12 months via a 120-item, selfadministered, food frequency questionnaire (45).

We assessed the preceding 12-month physical activity at baseline, and preceding 3-month physical activity at 3, 6, 9, and 12 months, among exercisers and controls. The baseline data were used to screen out individuals who were not sedentary. The physical activity interview was administered identically to intervention and control participants, using an adaptation of the MNLTPA, wherein participants reported whether they did any of the 38 recreational or 
household activities listed (56). For each activity performed, the participants were asked about the number of days per week and minutes per session over the relevant time interval. For eligibility, adherence, and control contamination estimation, we included only sports, recreational, and walking activities with a metabolic equivalent tests (MET) level $\geq 4.0$ (2) as exercise; activities associated with work or housework were not counted. As an objective measure of overall physical activity level, we asked all participants, exercisers and controls, to wear a pedometer during all waking hours for $7 \mathrm{~d}$, and to record the total number of steps each day at the end of the day on a provided log. Participants kept the logs for 7-d periods at prerandomization, and at 3-, 6-, 9- and 12-month follow-up.

$\mathrm{VO}_{2 \max }$ was assessed once each at baseline and 12 months. Participants completed a maximal graded treadmill test, with heart rate and oxygen uptake continuously monitored by a Medgraphics automated metabolic cart (Medgraphics, St. Paul, MN). The protocol was a modified branching treadmill protocol (51). The test began at $3.0 \mathrm{mph}$ and $0 \%$ grade, and the speed or grade of the treadmill increased $(0.5 \mathrm{mph}$ or $2 \%$ grade, respectively) every 2 min until the participant reached volitional fatigue and achieved a respiratory exchange ratio $>1.0$. For purposes of determining eligibility among men with a questionable reported exercise level at baseline, we classified as low fitness: $\mathrm{VO}_{2 \max }<37.0 \mathrm{~mL} \cdot \mathrm{kg}^{-1} \cdot \mathrm{min}^{-1}$ for ages 40-49 $\mathrm{yr}$; $\mathrm{V}_{2 \max }<33.0 \mathrm{~mL} \cdot \mathrm{kg}^{-1} \cdot \mathrm{min}^{-1}$ for ages $50-59 \mathrm{yr}$; and $\dot{\mathrm{VO}}_{2 \max }<31.0$ $\mathrm{mL} \cdot \mathrm{kg}^{-1} \cdot \mathrm{min}^{-1}$ for ages $60 \mathrm{yr}$ and older (fair to poor according to the American College of Sports Medicine guidelines (44).

With participants wearing light clothing, baseline, 3-, and 12-month weight and height to the nearest $0.1 \mathrm{~kg}$ and $0.1 \mathrm{~cm}$, respectively, were measured with a balance-beam scale and stadiometer. Both measurements were taken in duplicate and then averaged. At baseline and 12 months, total body fat and percent body fat were assessed using a DXA whole-body scanner (GE Lunar, Madison, WI).

At baseline, 3, and 12 months, participants provided a fasting 50-mL sample of blood, collected in the morning. Before blood draw, participants were asked to refrain from food or drink (except water) for $12 \mathrm{~h}$, exercise for $12 \mathrm{~h}$, smoking or taking NSAIDs for $24 \mathrm{~h}$, and drinking alcohol for $48 \mathrm{~h}$. Acute effects of exercise on sex hormones typically last only a few hours, but they can last up to $48 \mathrm{~h}$ (18). Acute exercise effects that persist beyond a few hours typically occur after quite intense exertion (i.e., marathon or triathlon competitions). Less intensive exercise typically induces acute changes for 1 to $2 \mathrm{~h}$ that do not persist $(19,48)$, as has been found particularly in older men undertaking similar exercise as in our study (66). Hence, observed changes from baseline to 3 or 12 months would most likely reflect chronic effects of exercise, although acute effects cannot entirely be excluded. Blood was processed within $1 \mathrm{~h}$ of collection, and serum was aliquoted into $1.8-\mathrm{mL}$ tubes and stored at $-70^{\circ} \mathrm{C}$. Date and time of collection were recorded, as well as time since each participant's last meal.

\section{Hormone assays}

Laboratory assays were performed at the reproductive endocrine research laboratory, University of Southern California (Frank Z. Stanczyk, director). Samples were placed into batches such that, within each batch, all samples from a participant were included, the numbers of exercise and control participants were approximately equal, the randomization dates of participants were similar, and the sample order was random. Two specimens of a control derived from pooled serum obtained from men disqualified from participation in the study were used to assure quality control. Laboratory personnel were blinded to sample identity. 
Testosterone, DHT, $3 \alpha$-Diol-G, and estradiol were quantified by radioimmunoassays after organic solvent extraction and Celite column partition chromatography $(15,47)$.

Chromatographic separation of the steroids was achieved by use of different concentrations of toluene in isooctane and ethyl acetate in isooctane. SHBG was quantified as previously described (38). Free testosterone and free estradiol were calculated using the measured values for SHBG and testosterone or estradiol, respectively, and an assumed constant for albumin $(54,62)$. The intra-assay and interassay coefficients of variation were as follows: testosterone 8.4\%, 9.3\%; DHT 5.7\%, 10.9\%; 3 $\alpha$-Diol-G 9.5\%, 11.0\%; SHBG 3.1\%, 3.8\%; estradiol $13.9 \%, 14.2 \%$.

\section{Statistical analyses}

Primary analyses were based on assigned treatment at the time of randomization, regardless of adherence or compliance status (i.e., intent to treat). We first assessed the baseline associations between hormones and several factors, including body mass index $\left(\mathrm{kg} \cdot \mathrm{m}^{-2}\right)$, percent body fat, and age with Spearman correlation coefficients. All hormones were nonnormally distributed, and therefore further data analyses were conducted on logtransformed values. We computed the baseline, 3-month, and 12-month geometric means of hormone end points (testosterone, free testosterone, DHT, $3 \alpha-$ Diol-G, estradiol, free estradiol, and SHBG) from baseline to 3 and 12 months. The analysis considered logtransformed hormone measures at baseline, 3 months, and 12 months as repeated measures, and assessed the intervention effects using a generalized estimating equation modification of the linear regression model, which allows us to compare changes from baseline to follow-up (64). Analyses are unadjusted because of the randomized design of the study. When assessing subgroups, we adjusted for age and BMI, but adjustment did not affect the results, and we therefore present unadjusted data.

Randomization led to 51 intervention participants and 51 control participants (Fig. 2). For secondary analyses, we assessed effect modification by baseline variables, including age (< $55 \mathrm{yr} ; \geq 55 \mathrm{yr})$, testosterone level $\left(<500 \mathrm{ng} \cdot \mathrm{dL}^{-1} ; \geq 500 \mathrm{ng} \cdot \mathrm{dL}^{-1}\right)$, BMI $\left(<30 \mathrm{~kg} \cdot \mathrm{m}^{-2} ; \geq 30\right.$ $\left.\mathrm{kg} \cdot \mathrm{m}^{-2}\right)$, body fat $(<30 \% ; \geq 30 \%), \mathrm{VO}_{2 \max }\left(\leq 30 \mathrm{~mL} \cdot \mathrm{kg}^{-1} \cdot \mathrm{min}^{-1} ;>30 \mathrm{~mL} \cdot \mathrm{kg}^{-1} \cdot \mathrm{min}^{-1}\right)$, and reported NSAID use (fewer than two times per week; two or more times per week). We also investigated the effect of change from baseline to 12 months in percent body fat (increased; decreased by $0-1.5 \%$; decreased by $>1.5 \%$ ), and, among exercisers, by minutes exercised per week from the daily activity $\operatorname{logs}(<300 ; 300-345 ;>345)$, and change in $\mathrm{VO}_{2 \max }(<5 \% ; 5-15 \% ;>15 \%)$.

All statistical tests were two sided. Statistical analyses were performed using Stata software (version 8; StataCorp, College Station, TX).

\section{RESULTS}

\section{Study participants}

At baseline, intervention and control groups were similar with regard to demographic characteristics, body composition, and fitness level (Table 1). Participants, on average, were $56 \mathrm{yr}$ old, were overweight/obese (mean baseline BMI $=29.9 \mathrm{~kg} \cdot \mathrm{m}^{-2}$ ), and had a low level of cardiopulmonary fitness $\left(\mathrm{VO}_{2 \max }\right)$. Approximately $94 \%$ were non-Hispanic white, and $60 \%$ had a college degree or higher.

To explore how adiposity relates to sex hormones, we examined the associations between markers of body fat content and hormone concentrations at baseline. Spearman coefficients between percent body fat (DXA) and testosterone, free testosterone, DHT, and SHBG were $-0.50(P<0.001),-0.46(P<0.001),-0.45(P<0.001)$, and $-0.38(P<0.001)$, respectively. Correlations between percent body fat and estradiol, free estradiol, and $3 \alpha-$ 
Diol-G were not statistically significant. Spearman coefficients for BMI and body weight with testosterone, free testosterone, DHT, and SHBG were similar to those of percent body fat. In addition, there were positive correlations between BMI or body weight and estradiol or free estradiol (ranging from 0.20 to 0.37 , all $P<0.05$ ). Baseline fitness as measured by $\mathrm{VO}_{2 \max }$ was significantly positively correlated with testosterone $(0.37, P<0.001)$, free testosterone (0.36, $P<0.001)$, DHT $(0.40, P<0.001)$, SHBG $(0.21, P=0.04)$, and negatively correlated with free estradiol $(-0.19, P=0.05)$. Finally, testosterone, free testosterone, DHT, and SHBG all correlated negatively with fasting insulin and glucose, with coefficients ranging from -0.19 to -0.42 (all $P<0.05$ ). Except for DHT and IGFBP-3 $(-0.21, P=0.03)$, there were no significant correlations between sex hormones and IGF-1 or IGFBP-3.

Adherence to the exercise intervention was excellent overall, with $80 \%$ of participants meeting $80 \%$ or more of their exercise goal of $360 \mathrm{~min} \cdot \mathrm{wk}^{-1}$ of structured aerobic exercise, according to exercise logs. Only 2 of 51 exercisers dropped the exercise intervention, both at 3 months. As reported in the MNLTPA interview, exercisers significantly increased their mean amount of moderate or vigorous recreational physical activity at each time period compared with baseline (baseline, 3-, 6-, 9-, and 12-month mean minutes per week of 26.8, $352,365,318$, and 301, respectively), and controls maintained their modest baseline recreational physical activity level (baseline, 3-, 6-, 9-, and 12-month mean minutes per week of 27.1, 98, 128, 96, and 82, respectively) ( $P<0.001$ for exercisers vs controls). One control participant indicated exercising at a moderate or vigorous level for more than 360 min. $\mathrm{wk}^{-1}$ (during the 12 months of follow-up); he was a "drop in" to the intervention. There were no differences between exercisers' and controls' reported mean total daily caloric intake as assessed via the food frequency questionnaire, which underreports caloric intake, and neither exercisers nor controls significantly changed reported food intake during the 12month study period (Table 2).

Averaged for the entire 12 months, exercisers completed a mean of $370 \pm 86 \mathrm{~min} \cdot \mathrm{wk}^{-1}$ ( $102.7 \%$ of goal), with a median of $318 \mathrm{~min} \cdot \mathrm{wk}^{-1}$. Improvements in fitness, body weight, and body composition were limited to the exercisers (Table 2) and have been published in detail previously (37). Exercisers lost $1.2 \mathrm{~kg}$ by 3 months, versus an increase of $0.4 \mathrm{~kg}$ in controls $(P=0.002)$. Exercisers reduced their BMI at 3 months by $0.4 \mathrm{~kg} \cdot \mathrm{m}^{-2}$, versus an increase of $0.1 \mathrm{~kg} \cdot \mathrm{m}^{-2}$ in controls $(P=0.003)$. Waist circumference decreased in exercisers by $2 \mathrm{~cm}$ after 3 months versus an increase of $0.6 \mathrm{~cm}$ in controls $(P=0.001)$. Hip circumference decreased in exercisers by $1 \mathrm{~cm}$ after 3 months versus an increase of $0.8 \mathrm{~cm}$ in controls $(P=0.002)$. At 12 months, $\mathrm{VO}_{2 \max }$ increased $10.8 \%$ in exercisers and decreased $1.8 \%$ in controls $(P<0.001)$. Exercisers lost $1.8 \mathrm{~kg}$ by 12 months, versus $0.1 \mathrm{~kg}$ among controls $(P=0.03)$. Fat mass decreased in exercisers by $2.9 \mathrm{~kg}$ after 12 months versus an increase of $0.2 \mathrm{~kg}$ in controls $(P<0.001)$. Lean mass increased in exercisers by $0.8 \mathrm{~kg}$ after 12 months versus a decrease of $0.2 \mathrm{~kg}$ in controls $(P=0.016)$.

Exercisers had significantly increased DHT and SHBG levels at 3 and 12 months after randomization when compared with controls (Table 3). Men in the exercise group experienced a $14.5 \%$ increase in DHT at 3 months, compared with a $1.7 \%$ increase among controls (exercisers vs controls $P=0.04$ ). At 12 months, the mean DHT level in the exercise group remained elevated above baseline by $8.6 \%$ compared with a decrease of $3.1 \%$ among controls (exercisers vs controls $P=0.03$ ). At 3 months, exercisers experienced a $14.3 \%$ increase in SHBG $(P<0.001)$ compared with a more modest, but still significant, $5.7 \%$ increase among controls $(P=0.04$, exercisers vs controls $P=0.04)$. Exercisers at 12 months maintained a consistent, significant $8.9 \%$ elevation of SHBG $(P=0.001)$ compared with a nonsignificant $4.0 \%$ elevation above baseline among controls (exercisers vs controls $P=$ 
0.13). There were no significant differences between exercisers and controls for testosterone, free testosterone, $3 \alpha$-Diol-G, estradiol, or free estradiol.

Exploratory subanalyses considering effect modification by baseline variables including age, testosterone level, NSAID use, BMI, percent body fat, and $\mathrm{VO}_{2 \max }$ on the exercise-induced changes in sex hormones were conducted. There was no evidence for modification of the study intervention effect on sex hormones by any of these variables (data not shown). We could not explore effect modification attributable to smoking because of the small number of smokers in our study. Analyses were rerun with smokers excluded, and there were no differences in our findings; hence, smokers were included in our reported results (data not shown).

A priori, we planned to analyze changes in sex hormones by both change in percent body fat and by intervention adherence (change in $\mathrm{VO}_{2 \max }$ and minutes per week). Surprisingly, there were no significant effects of body fat change on DHT or SHBG between exercisers and controls (Table 4). DHT increased to the greatest degree among exercisers and controls who lost the greatest amount of body fat, whereas among those who lost small amounts of fat or gained fat, DHT increased slightly, and only among exercisers. Exercisers and controls in all categories of change in percent fat experienced increases in SHBG, although there were no patterns across categories of change in body fat.

Adherence to the study intervention as evidenced by improvement in $\mathrm{VO}_{2 \max }$ did modify the findings for DHT and SHBG (Table 5). At 3 months, exercisers who had $>15 \%$ increase in $\mathrm{VO}_{2 \max }$ experienced the greatest increases in DHT (22.0\% increase vs $1.7 \%$ among controls, $P=0.002)$ and SHBG $(20.2 \%$ increase vs $5.7 \%$ increase among controls, $P=$ 0.002 ). These patterns persisted at 12 months, where exercisers who maintained $>15 \%$ increase in $\mathrm{VO}_{2 \max }$ had a $25.7 \%$ increase in DHT compared with a $3.1 \%$ decrease among controls $(P<0.001)$, and a $16.5 \%$ increase in SHBG compared with a $4.0 \%$ increase among controls $(P=0.02)$. The analyses for change in DHT and SHBG by minutes per week of exercise were similar to findings for change in $\mathrm{VO}_{2 \max }$ (data not shown).

\section{DISCUSSION}

This randomized, controlled clinical trial showed that a 12-month moderate-to-vigorous aerobic exercise intervention increased circulating DHT levels among exercisers versus controls at 3 and 12 months. Additionally, SHBG was significantly greater among exercisers versus controls at 3 months, although the continued elevation in SHBG at 12 months was only significant when compared with exercisers' baseline levels. Further, DHT and SHBG increased most substantially among exercisers who experienced the greatest change in cardiopulmonary fitness as measured by $\mathrm{VO}_{2 \mathrm{max}}$. We found no significant effects of this exercise intervention on testosterone, free testosterone, $3 \alpha$-Diol-G, estradiol, or free estradiol.

When measured after a short-term, acute bout of exercise, testosterone levels typically increase transiently, though this finding is not universal $(14,18,20,31,63)$. In some studies, elevations in free testosterone, bioavailable testosterone, SHBG, and other androgens such as dihydroepiandosterone have also been observed, but the hormone changes are variable and may depend on the exercise paradigm (resistance vs aerobic), the exercise intensity, and/ or the study population (young vs older men) $(4,20,53,58)$. When testosterone levels are compared cross-sectionally between middle-aged and older men who have engaged in longterm exercise versus those who have not, testosterone levels are higher among regular exercisers $(3,40)$, with similar findings for SHBG (10). However, among highly trained endurance athletes, testosterone levels have also been found to be lower than among either 
resistance-trained or control subjects, introducing the possibility of exercise-related sex hormone dysfunction (17). We found no effect of our 12-month moderate-to-vigorous aerobic training program on circulating testosterone levels, suggesting that it is unlikely testosterone would mediate the beneficial effects of this type of exercise such as altered body composition or improved bone health. However, we also did not detect a decrease in testosterone that would be considered deleterious to men's health.

We did find a significant increase in the more biologically active androgen, DHT, with exercise in our randomized trial. This is the first study, to our knowledge, to demonstrate such an effect. DHT is most commonly formed at the tissue level, by $5 \alpha$-reduction of testosterone, while circulating DHT is largely bound to SHBG (28). Age may influence DHT levels, but both positive (13) and negative (11) correlations have been reported. Similar to testosterone, low DHT is associated with higher body fat content $(1,21,22,29,52,59)$, and we also observed this negative correlation among our participants at baseline. Loss of fat mass could be one mechanism through which DHT increased among men in the exercise group. Both $3 \alpha$-HSD-3, which converts DHT to $3 \alpha$-Diol, and UGT2B15, which converts $3 \alpha$-Diol to $3 \alpha$-Diol-G, are found in adipose tissue $(5,57)$. In a study of $3 \alpha-$ HSD-3 in subcutaneous and omental adipose tissue from lean and obese men, local androgen inactivation was a predominant reaction in both subcutaneous and omental adipose tissue, but the greatest activity of $3 \alpha$-HSD-3 occurred in omental adipocytes from the obese men (7). Surprisingly, we did not find that DHT increases were greater among men who lost more fat in our study. Instead, those who had the greatest improvements in fitness, as measured by $\mathrm{VO}_{2 \max }$, experienced the greatest increases in DHT. This finding suggests that physiologic pathways might exist for exercise to affect DHT other than altered fat mass.

Given the association of elevated androgens, particularly DHT, with increased prostate cancer risk (9), the rise in DHT with exercise that occurred in our study might be of concern. However, one recent epidemiologic study has found that low DHT is associated with decreased prostate cancer survival among men with screening-detected cancer (30), and, further, lower levels of intraprostatic DHT are associated with greater cancer aggressiveness (43). Some researchers hypothesize that aromatization of testosterone to estrogen may play a key role in prostate carcinogenesis, and, because DHT cannot be aromatized to estrogen, its role may not be as critical to cancer pathogenesis (9). In fact, increased DHT may actually mediate favorable metabolic effects. In bone, enzymes that glucuronidate sex steroids are associated with both higher levels of DHT and cortical bone size, at least among young men (55). Further, low levels of DHT have been associated with ischemic heart disease mortality. Given the potential benefits of increased DHT, additional studies that corroborate our findings and that could explore mechanisms mediating the increase in DHT are warranted.

Although we only found a significant increase in SHBG in exercisers versus controls at 3 months, the persistent elevation among exercisers (with a trend towards a difference vs controls) at 12 months is provocative in light of recent research suggesting a role for SHBG in insulin resistance and metabolic syndrome $(27,33-35,41)$. SHBG is inhibited by insulin $(1,46)$, and SHBG levels are low in states of insulin resistance (35). In a prospective study, researchers found that lower levels of SHBG were associated with an increased risk of developing metabolic syndrome among men ages 40-70 during a 15-yr follow-up period, particularly among those with lower BMI (33). Mechanisms by which SHBG might mediate this effect are not known, but teasing out the independent role of SHBG versus its status as a marker of insulin resistance is difficult. In our study, SHBG levels were negatively correlated with body fat and insulin levels at baseline. Certainly, a loss of fat mass could explain the greater increase in SHBG seen in exercisers, because this should lower insulin levels and, therefore, reverse the inhibition of SHBG production. Yet, as with our DHT findings, we did not find that SHBG increases were greater among men who lost more fat. 
We saw that those who had the greatest improvements in $\dot{\mathrm{VO}}_{2 \max }$ experienced the greatest increases in SHBG. This again suggests that other physiologic pathways exist for exercise to affect SHBG than altered fat mass, though these effects may still be mediated via improvements in insulin sensitivity. When obese men were placed on a low-fat, highcomplex carbohydrate diet in conjunction with daily aerobic exercise, serum insulin at $3 \mathrm{wk}$ was reduced, whereas SHBG increased (60). Additional research designed to tease out the physiologic mechanisms underlying the effect of exercise on SHBG independent of dietary change is needed.

Limitations of our study include a relatively small sample size, which may have reduced the power to explore subgroups for effect modification. Additionally, our study participants were primarily Caucasian men from higher socioeconomic status than the general population, who were well connected to the health care system. Thus, it may not be prudent to generalize the conclusions of the present study to a broader group of men. Further, exercise performed at home was self-reported compared with observed exercise performed at the facility. Nonetheless, the significant increase in $\mathrm{V}_{2 \max }$ found only among exercisers attests to the high overall level of adherence. For each study time point, blood was drawn only once; therefore, there is only one measure of hormone levels at baseline and at 3 and 12 months to represent the exercise effect on sex hormones. Because of the significant diurnal variation in serum androgens (28), we completed all blood draws in the early morning. An additional strength of our study was our measurement of a comprehensive panel of sex hormones. Finally, we conducted a randomized clinical trial with excellent adherence and retention.

In summary, this 12 -month, randomized, controlled trial testing a moderate- to vigorousintensity exercise intervention resulted in significant increases in DHT and, to a lesser extent, SHBG among middle-aged and older men. Greater increases were found with greater improvements in cardiopulmonary fitness. Given the controversy surrounding exogenous androgen supplementation, modest enhancement of DHT levels in middle-aged and elderly obese men through exercise may offer a lower-risk approach for improved health.

\section{Acknowledgments}

This manuscript work was funded through NCI grants P20 CA 103728, R01 CA77572, and the Seattle Transdisciplinary Research on Energetics and Cancer (TREC) grant (NCI U54 CA116847). Ms. Hawkins was funded in part through an NIH training grant R25 CA94880. Dr. Foster-Schubert is partially funded by K12 RR023265-03 (NCRR). The contents of the manuscript are solely the responsibility of the authors and do not necessarily represent the official view of the NIH. We wish to thank Lilly Chang, MD, for technical assistance in hormone determinations, and the participants from A Program Promoting Exercise and Active Lifestyles (APPEAL) for their dedication.

\section{References}

1. Abate N, Haffner SM, Garg A, Peshock RM, Grundy SM. Sex steroid hormones, upper body obesity, and insulin resistance. J Clin Endocrinol Metab 2002;87(10):4522-7. [PubMed: 12364429]

2. Ainsworth BE, Haskell WL, Whitt MC, et al. Compendium of physical activities: an update of activity codes and MET intensities. Med Sci Sports Exerc 2000;32(9 suppl):S498-504. [PubMed: 10993420]

3. Ari Z, Kutlu N, Uyanik BS, Taneli F, Buyukyazi G, Tavli T. Serum testosterone, growth hormone, and insulin-like growth factor-1 levels, mental reaction time, and maximal aerobic exercise in sedentary and long-term physically trained elderly males. Int J Neurosci 2004;114(5):623-37. [PubMed: 15204068]

4. Baker JR, Bemben MG, Anderson MA, Bemben DA. Effects of age on testosterone responses to resistance exercise and musculoskeletal variables in men. J Strength Cond Res 2006;20(4):874-81. [PubMed: 17194250] 
5. Belanger C, Luu-The V, Dupont P, Tchernof A. Adipose tissue intracrinology: potential importance of local androgen/estrogen metabolism in the regulation of adiposity. Horm Metab Res 2002;34(1112):737-45. [PubMed: 12660892]

6. Bhasin S, Cunningham GR, Hayes FJ, et al. Testosterone therapy in adult men with androgen deficiency syndromes: an endocrine society clinical practice guideline. J Clin Endocrinol Metab 2006;91(6):1995-2010. [PubMed: 16720669]

7. Blouin K, Richard C, Brochu G, et al. Androgen inactivation and steroid-converting enzyme expression in abdominal adipose tissue in men. J Endocrinol 2006;191(3):637-49. [PubMed: 17170221]

8. Bonifazi M, Bela E, Carli G, et al. Influence of training on the response of androgen plasma concentrations to exercise in swimmers. Eur J Appl Physiol Occup Physiol 1995;70(2):109-14. [PubMed: 7768232]

9. Bosland MC. Sex steroids and prostate carcinogenesis: integrated, multifactorial working hypothesis. Ann N Y Acad Sci 2006;1089:168-76. [PubMed: 17261765]

10. Cooper CS, Taaffe DR, Guido D, Packer E, Holloway L, Marcus R. Relationship of chronic endurance exercise to the somatotropic and sex hormone status of older men. Eur J Endocrinol 1998;138(5):517-23. [PubMed: 9625362]

11. Couillard C, Gagnon J, Bergeron J, et al. Contribution of body fatness and adipose tissue distribution to the age variation in plasma steroid hormone concentrations in men: the HERITAGE Family Study. J Clin Endocrinol Metab 2000;85(3):1026-31. [PubMed: 10720034]

12. Davidson JM, Chen JJ, Crapo L, Gray GD, Greenleaf WJ, Catania JA. Hormonal changes and sexual function in aging men. J Clin Endocrinol Metab 1983;57(1):71-7. [PubMed: 6602143]

13. Feldman HA, Longcope C, Derby CA, et al. Age trends in the level of serum testosterone and other hormones in middle-aged men: longitudinal results from the Massachusetts male aging study. $\mathrm{J}$ Clin Endocrinol Metab 2002;87(2):589-98. [PubMed: 11836290]

14. Fellmann N, Coudert J, Jarrige JF, et al. Effects of endurance training on the androgenic response to exercise in man. Int J Sports Med 1985;6(4):215-9. [PubMed: 4044106]

15. Goebelsmann, U.; Bernstein, GS.; Gale, JA., et al. Serum gonadotropin, testosterone, estradiol and estrone levels prior to and following bilateral vasectomy. In: Lepow, IH.; Crozier, R., editors. Vasectomy: Immunologic and Pathophysiologic Effects in Animals and Man. New York (NY): Academic Press; 1979. p. 165

16. Gruenewald DA, Matsumoto AM. Testosterone supplementation therapy for older men: potential benefits and risks. J Am Geriatr Soc 2003;51(1):101-15. [PubMed: 12534854]

17. Hackney AC. Endurance exercise training and reproductive endocrine dysfunction in men: alterations in the hypothalamic-pituitary-testicular axis. Curr Pharm Des 2001;7(4):261-73. [PubMed: 11254889]

18. Hackney AC, Fahrner CL, Gulledge TP. Basal reproductive hormonal profiles are altered in endurance trained men. J Sports Med Phys Fitness 1998;38(2):138-41. [PubMed: 9763799]

19. Hackney AC, Ness RJ, Schrieber A. Effects of endurance exercise on nocturnal hormone concentrations in males. Chronobiol Int 1989;6(4):341-6. [PubMed: 2627720]

20. Hackney AC, Premo MC, McMurray RG. Influence of aerobic versus anaerobic exercise on the relationship between reproductive hormones in men. J Sports Sci 1995;13(4):305-11. [PubMed: 7474044]

21. Haffner SM, Karhapaa P, Mykkanen L, Laakso M. Insulin resistance, body fat distribution, and sex hormones in men. Diabetes 1994;43(2):212-9. [PubMed: 8288045]

22. Haffner SM, Valdez RA, Stern MP, Katz MS. Obesity, body fat distribution and sex hormones in men. Int J Obes Relat Metab Disord 1993;17(11):643-9. [PubMed: 8281222]

23. Hak AE, Witteman JC, de Jong FH, Geerlings MI, Hofman A, Pols HA. Low levels of endogenous androgens increase the risk of atherosclerosis in elderly men: the Rotterdam study. J Clin Endocrinol Metab 2002;87(8):3632-9. [PubMed: 12161487]

24. Herbst KL, Bhasin S. Testosterone action on skeletal muscle. Curr Opin Clin Nutr Metab Care 2004;7(3):271-7. [PubMed: 15075918]

25. Hijazi RA, Cunningham GR. Andropause: is androgen replacement therapy indicated for the aging male? Annu Rev Med 2005;56:117-37. [PubMed: 15660505] 
26. Izquierdo M, Hakkinen K, Ibanez J, et al. Effects of strength training on muscle power and serum hormones in middle-aged and older men. J Appl Physiol 2001;90(4):1497-507. [PubMed: 11247952]

27. Kalme T, Seppala M, Qiao Q, et al. Sex hormone-binding globulin and insulin-like growth factorbinding protein-1 as indicators of metabolic syndrome, cardiovascular risk, and mortality in elderly men. J Clin Endocrinol Metab 2005;90(3):1550-6. [PubMed: 15613437]

28. Kaufman JM, Vermeulen A. The decline of androgen levels in elderly men and its clinical and therapeutic implications. Endocr Rev 2005;26(6):833-76. [PubMed: 15901667]

29. Khaw KT, Barrett-Connor E. Lower endogenous androgens predict central adiposity in men. Ann Epidemiol 1992;2(5):675-82. [PubMed: 1342319]

30. Kjellman A, Akre O, Norming U, Tornblom M, Gustafsson O. Dihydrotestosterone levels and survival in screening-detected prostate cancer: a 15-yr follow-up study. Eur Urol 2008;53(1):10611. [PubMed: 17482753]

31. Kraemer WJ, Hakkinen K, Newton RU, et al. Acute hormonal responses to heavy resistance exercise in younger and older men. Eur J Appl Physiol Occup Physiol 1998;77(3):206-11. [PubMed: 9535580]

32. Kraemer WJ, Ratamess NA. Hormonal responses and adaptations to resistance exercise and training. Sports Med 2005;35(4):339-61. [PubMed: 15831061]

33. Kupelian V, Page ST, Araujo AB, Travison TG, Bremner WJ, McKinlay JB. Low sex hormonebinding globulin, total testosterone, and symptomatic androgen deficiency are associated with development of the metabolic syndrome in nonobese men. J Clin Endocrinol Metab 2006;91(3): 843-50. [PubMed: 16394089]

34. Laaksonen DE, Niskanen L, Punnonen K, et al. Testosterone and sex hormone-binding globulin predict the metabolic syndrome and diabetes in middle-aged men. Diabetes Care 2004;27(5): 1036-41. [PubMed: 15111517]

35. Lewis JG, Shand BI, Elder PA, Scott RS. Plasma sex hormone-binding globulin rather than corticosteroid-binding globulin is a marker of insulin resistance in obese adult males. Diabetes Obes Metab 2004;6(4):259-63. [PubMed: 15171749]

36. Liu PY, Death AK, Handelsman DJ. Androgens and cardiovascular disease. Endocr Rev 2003;24(3):313-40. [PubMed: 12788802]

37. McTiernan A, Sorensen B, Irwin ML, et al. Exercise effect on weight and body fat in men and women. Obesity (Silver Spring) 2007;15(6):1496-512. [PubMed: 17557987]

38. McTiernan A, Tworoger SS, Rajan KB, et al. Effect of exercise on serum androgens in postmenopausal women: a 12-month randomized clinical trial. Cancer Epidemiol Biomarkers Prev 2004;13(7):1099-105. [PubMed: 15247119]

39. McTiernan A, Yasui Y, Sorensen B, et al. Effect of a 12-month exercise intervention on patterns of cellular proliferation in colonic crypts: a randomized controlled trial. Cancer Epidemiol Biomarkers Prev 2006;15(9):1588-97. [PubMed: 16985018]

40. Muller M, den Tonkelaar I, Thijssen JH, Grobbee DE, van der Schouw YT. Endogenous sex hormones in men aged 40-80 years. Eur J Endocrinol 2003;149(6):583-9. [PubMed: 14641001]

41. Muller M, Grobbee DE, den Tonkelaar I, Lamberts SW, van der Schouw YT. Endogenous sex hormones and metabolic syndrome in aging men. J Clin Endocrinol Metab 2005;90(5):2618-23. [PubMed: 15687322]

42. Nicklas BJ, Ryan AJ, Treuth MM, et al. Testosterone, growth hormone and IGF-I responses to acute and chronic resistive exercise in men aged 55-70 years. Int J Sports Med 1995;16(7):44550. [PubMed: 8550252]

43. Nishiyama T, Ikarashi T, Hashimoto Y, Suzuki K, Takahashi K. Association between the dihydrotestosterone level in the prostate and prostate cancer aggressiveness using the Gleason score. J Urol 2006;176(4 Pt 1):1387-91. [PubMed: 16952639]

44. Pate, R. Guidelines for Exercise Testing and Prescription. Philadelphia (PA): Lea and Febiger; 1991. p. 70-72.

45. Patterson RE, Kristal AR, Tinker LF, Carter RA, Bolton MP, Agurs-Collins T. Measurement characteristics of the Women's Health Initiative food frequency questionnaire. Ann Epidemiol 1999;9(3):178-87. [PubMed: 10192650] 
46. Plymate SR, Matej LA, Jones RE, Friedl KE. Inhibition of sex hormone-binding globulin production in the human hepatoma (Hep G2) cell line by insulin and prolactin. J Clin Endocrinol Metab 1988;67(3):460-4. [PubMed: 2842359]

47. Probst-Hensch NM, Ingles SA, Diep AT, et al. Aromatase and breast cancer susceptibility. Endocr Relat Cancer 1999;6(2):165-73. [PubMed: 10731105]

48. Raastad T, Bjoro T, Hallen J. Hormonal responses to high- and moderate-intensity strength exercise. Eur J Appl Physiol 2000;82(1-2):121-8. [PubMed: 10879453]

49. Russell DW, Wilson JD. Steroid 5 alpha-reductase: two genes/two enzymes. Annu Rev Biochem 1994;63:25-61. [PubMed: 7979239]

50. Sallinen J, Hoglund I, Engstrom M, et al. Pharmacological characterization and CNS effects of a novel highly selective alpha2C-adrenoceptor antagonist JP-1302. Br J Pharmacol 2007;150(4): 391-402. [PubMed: 17220913]

51. Schauer JE, Hanson P. Usefulness of a branching treadmill protocol for evaluation of cardiac functional capacity. Am J Cardiol 1987;60(16):1373-7. [PubMed: 3687788]

52. Seidell JC, Bjorntorp P, Sjostrom L, Kvist H, Sannerstedt R. Visceral fat accumulation in men is positively associated with insulin, glucose, and C-peptide levels, but negatively with testosterone levels. Metabolism 1990;39(9):897-901. [PubMed: 2202881]

53. Smilios I, Pilianidis T, Karamouzis M, Parlavantzas A, Tokmakidis SP. Hormonal responses after a strength endurance resistance exercise protocol in young and elderly males. Int J Sports Med 2007;28(5):401-6. [PubMed: 17024619]

54. Sodergard R, Backstrom T, Shanbhag V, Carstensen H. Calculation of free and bound fractions of testosterone and estradiol-17 beta to human plasma proteins at body temperature. J Steroid Biochem 1982;16(6):801-10. [PubMed: 7202083]

55. Swanson C, Lorentzon M, Vandenput L, et al. Sex steroid levels and cortical bone size in young men is associated with a glucuronidation enzyme UGT2B7 polymorphism (H268Y). J Clin Endocrinol Metab 2007;92(9):3697-704. [PubMed: 17579197]

56. Taylor HL, Jacobs DR Jr, Schucker B, Knudsen J, Leon AS, Debacker G. A questionnaire for the assessment of leisure time physical activities. J Chronic Dis 1978;31(12):741-55. [PubMed: 748370]

57. Tchernof A, Levesque E, Beaulieu M, et al. Expression of the androgen metabolizing enzyme UGT2B15 in adipose tissue and relative expression measurement using a competitive RT-PCR method. Clin Endocrinol (Oxf) 1999;50(5):637-42. [PubMed: 10468930]

58. Tremblay MS, Copeland JL, Van Helder W. Effect of training status and exercise mode on endogenous steroid hormones in men. J Appl Physiol 2004;96(2):531-9. [PubMed: 14514704]

59. Tsai EC, Boyko EJ, Leonetti DL, Fujimoto WY. Low serum testosterone level as a predictor of increased visceral fat in Japanese-American men. Int J Obes Relat Metab Disord 2000;24(4):48591. [PubMed: 10805506]

60. Tymchuk CN, Tessler SB, Aronson WJ, Barnard RJ. Effects of diet and exercise on insulin, sex hormone-binding globulin, and prostate-specific antigen. Nutr Cancer 1998;31(2):127-31. [PubMed: 9770724]

61. Vermeulen A. Clinical review 24: androgens in the aging male. J Clin Endocrinol Metab 1991;73(2):221-4. [PubMed: 1856256]

62. Vermeulen A, Verdonck L, Kaufman JM. A critical evaluation of simple methods for the estimation of free testosterone in serum. J Clin Endocrinol Metab 1999;84(10):3666-72. [PubMed: 10523012]

63. Willoughby DS, Taylor L. Effects of sequential bouts of resistance exercise on androgen receptor expression. Med Sci Sports Exerc 2004;36(9):1499-506. [PubMed: 15354030]

64. Zeger SL, Liang KY. Longitudinal data analysis for discrete and continuous outcomes. Biometrics 1986;42(1):121-30. [PubMed: 3719049]

65. Zmuda JM, Cauley JA, Kriska A, Glynn NW, Gutai JP, Kuller LH. Longitudinal relation between endogenous testosterone and cardiovascular disease risk factors in middle-aged men. A 13-year follow-up of former Multiple Risk Factor Intervention Trial participants. Am J Epidemiol 1997;146(8):609-17. [PubMed: 9345114] 
66. Zmuda JM, Thompson PD, Winters SJ. Exercise increases serum testosterone and sex hormonebinding globulin levels in older men. Metabolism 1996;45(8):935-9. [PubMed: 8769347] 


\section{FIGURE 1.}

Testosterone metabolism. Type $25 \alpha$-reductase is found predominantly in the prostate and other genital tissues and is believed to be more important in conversion of testosterone to DHT, whereas type 1 is found throughout the body, including the skin, liver, and prostate (49). $3 \alpha$-Diol-G is a metabolite of DHT. Type $33 \alpha$-hydroxysteroid dehydrogenase ( $3 \alpha-$ HSD-3) converts DHT to $3 \alpha$-androstanediol ( $3 \alpha$-Diol), the immediate precursor of $3 \alpha$-Diol$\mathrm{G}$, and is found in abdominal adipose tissue (46). $3 \alpha$-Diol is converted to $3 \alpha$-Diol-G by the glucuro(39)nosyltransferase UGT2B15, an enzyme also present in fat tissue (57). 


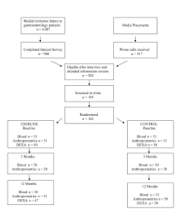

FIGURE 2.

Participant recruitment, screening, randomization, and retention. 
TABLE 1

Baseline characteristics of study participants.

\begin{tabular}{lcc}
\hline & Exercisers, Mean (SD) & Controls, Mean (SD) \\
\hline$N$ & 51 & 51 \\
Age $(\mathrm{yr})$ & $56.2(6.7)$ & $56.6(7.6)$ \\
Body mass index $\left(\mathrm{kg} \cdot \mathrm{m}^{-2}\right)$ & $29.7(3.7)$ & $30.1(4.8)$ \\
Percent body fat $(\mathrm{DEXA})$ & $31.5(6.4)$ & $29.7(6.0)$ \\
$\mathrm{VO}_{2 \mathrm{max}}\left(\mathrm{mL} \cdot \mathrm{kg}^{-1} \cdot \mathrm{min}^{-1}\right)$ & $30.1(5.9)$ & $30.3(6.7)$ \\
Steps per day & $5967(2778)$ & $6180(3236)$ \\
Total calories $\left(\mathrm{kcal} \cdot \mathrm{d}^{-1}\right)$ & $1692(639)$ & $1668(566)$ \\
& $\boldsymbol{N}(\%)$ & $\mathbf{N}(\%)$ \\
Education: college degree or more Ethnicity & $33(64.7)$ & $28(54.9)$ \\
$\quad$ Non-Hispanic white & $48(94.1)$ & $48(94.1)$ \\
Asian/Pacific Islander & $3(5.9)$ & $2(3.9)$ \\
Other & $0(0)$ & $1(2.0)$ \\
Smoker & $5(9.8)$ & $4(7.8)$ \\
NSAID use & & $29(56.9)$ \\
$<23 \mathrm{wk}{ }^{-1}$ & $29(56.9)$ & $22(43.1)$ \\
$\geq 23 \mathrm{wk}$ & $22(43.1)$ &
\end{tabular}

Two exercisers and one control are missing baseline DXA and FFQ. These participants are excluded from the analyses for these variables. 
TABLE 2

Baseline and 12-month change in measures of body composition, fitness, and adherence for study participants.

\begin{tabular}{|c|c|c|}
\hline & Exercisers, Mean (SD) & Controls, Mean (SD) \\
\hline Body weight (kg) & $94.8(14.9)$ & $97.4(18.2)$ \\
\hline Change at 12 months & $-1.8(4.3)$ & $-0.1(3.6)$ \\
\hline Body mass index $\left(\mathrm{kg} \cdot \mathrm{m}^{-2}\right)$ & $29.7(3.7)$ & $30.1(4.8)$ \\
\hline Change at 12 months & $-0.6(1.3)$ & $0.0(1.1)$ \\
\hline Percent body fat (DXA) & $31.5(6.4)$ & $29.7(6.0)$ \\
\hline Change at 12 months & $-2.6(3.1)$ & $0.2(1.7)$ \\
\hline $\mathrm{VO}_{2 \max }\left(\mathrm{mL} \cdot \mathrm{kg}^{-1} \cdot \mathrm{min}^{-1}\right)$ & $30.1(5.9)$ & $30.3(6.7)$ \\
\hline Change at 12 months & $3.1(3.2)$ & $-0.9(3.4)$ \\
\hline Total calories $\left(\mathrm{kcal} \cdot \mathrm{d}^{-1}\right)$ & $1692(639)$ & $1668(566)$ \\
\hline Change at 12 months & $-99(496)$ & $-123(641)$ \\
\hline Steps per day & $5967(2778)$ & $6180(3236)$ \\
\hline Change at 12 months & $3118(3042)$ & $474(3141)$ \\
\hline \multicolumn{3}{|c|}{ Minutes per week of moderate-to-vigorous exercise (logs) } \\
\hline Baseline to 3 months & $237(53)$ & N/A \\
\hline Baseline to 12 months & $370(86)$ & N/A \\
\hline \multicolumn{3}{|c|}{ Days per week of moderate-to-vigorous exercise (logs) } \\
\hline Baseline to 3 months & $5.6(1.1)$ & N/A \\
\hline Baseline to 12 months & $6.3(1.9)$ & N/A \\
\hline \multicolumn{3}{|c|}{ Minutes per week of moderate-to-vigorous as \% of goal (logs) } \\
\hline Baseline to 3 months & $102(26)$ & $\mathrm{N} / \mathrm{A}$ \\
\hline Baseline to 12 months & $119(29)$ & N/A \\
\hline
\end{tabular}

Two exercisers and one control are missing baseline DXA and FFQ. These participants are excluded from the analyses for these variables. 


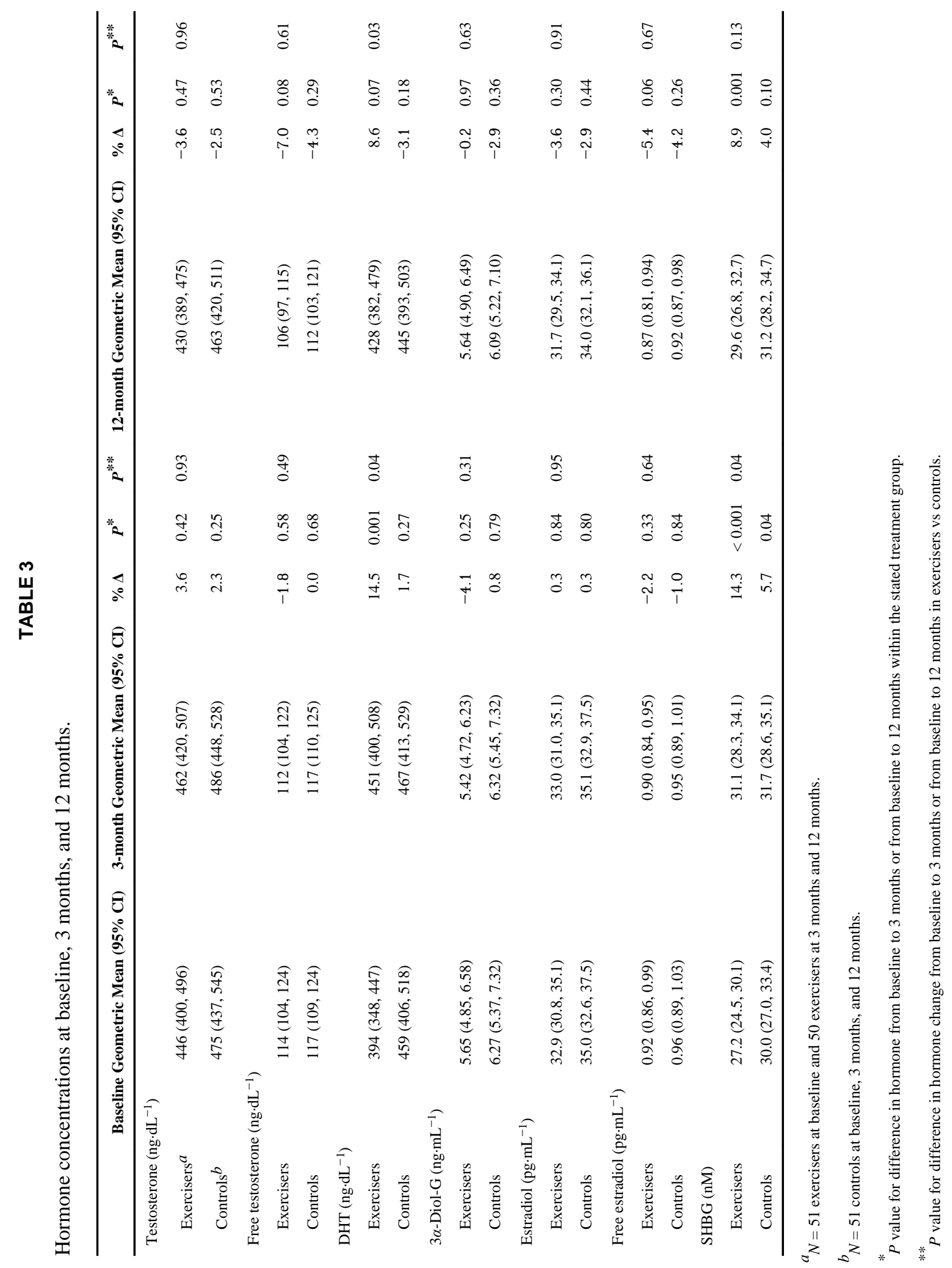




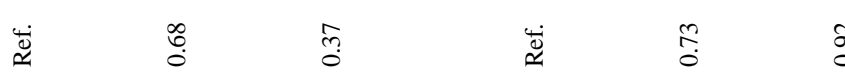

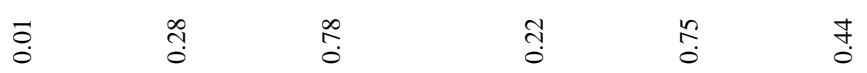

$$
\begin{aligned}
& \text { i }
\end{aligned}
$$

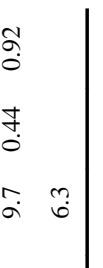

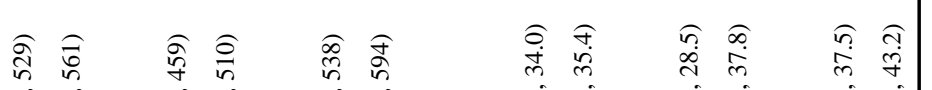

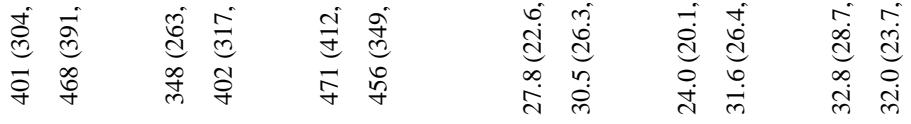

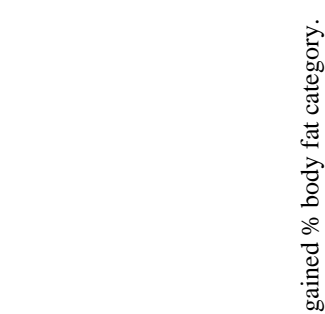

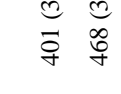$$
\text { 崩 }
$$$$
\text { กิ }
$$

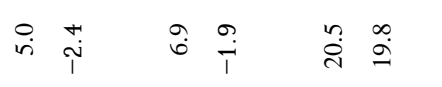

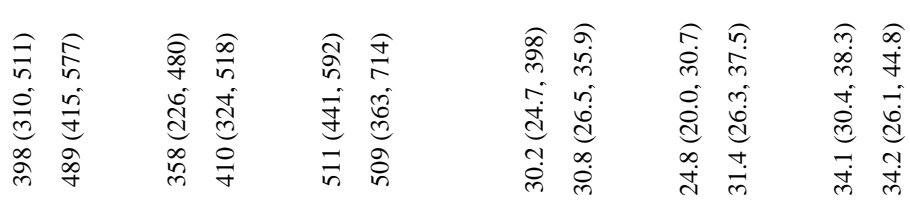

$$
\begin{aligned}
& \text { ๕্য } \\
& \text { ๕. ปี กิ }
\end{aligned}
$$

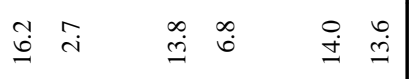




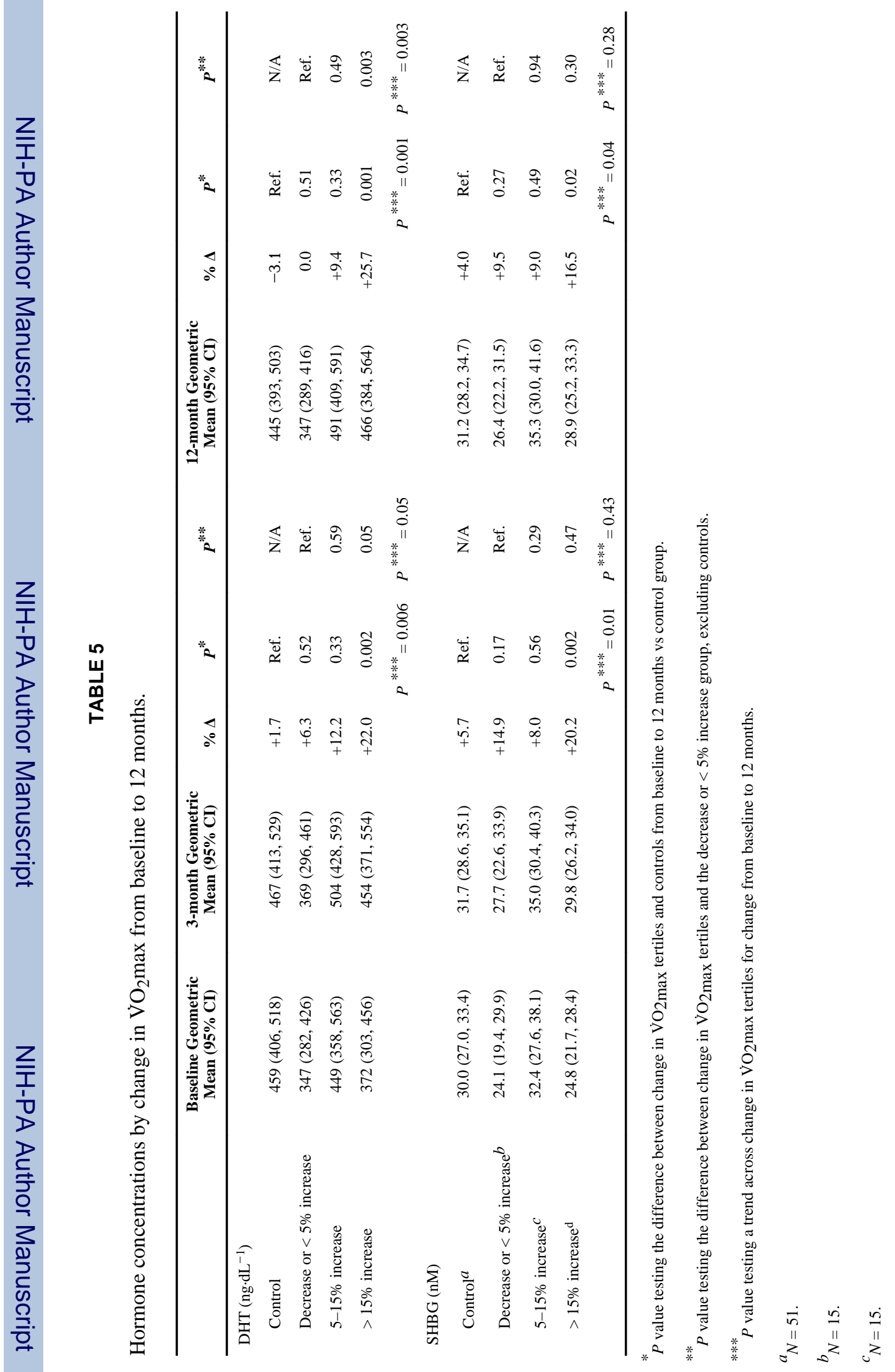

Med Sci Sports Exerc. Author manuscript; available in PMC 2011 February 16. 